\title{
Labyrinthe
}

$11 \mid 2002$

Numéro 11

\section{Valeurs et valorisations du territoire}

Article collectif

Maria Basile, Anne Douvin, Harold Hurel, Karim Mosbah, France Poulain, Chakib Benramdane, Yann Renaud and Clément Orillard

\section{(2) OpenEdition}

Journals

Electronic version

URL: http://journals.openedition.org/labyrinthe/652

DOI: $10.4000 /$ labyrinthe.652

ISSN: 1950-6031

Publisher

Hermann

\section{Printed version}

Date of publication: 14 January 2002

Number of pages: $27-50$

Electronic reference

Maria Basile, Anne Douvin, Harold Hurel, Karim Mosbah, France Poulain, Chakib Benramdane, Yann Renaud and Clément Orillard, «Valeurs et valorisations du territoire », Labyrinthe [Online], 11 | 2002, Online since 14 April 2005, connection on 19 April 2019. URL : http://journals.openedition.org/ labyrinthe/652 ; DOI : 10.4000/labyrinthe.652

This text was automatically generated on 19 April 2019

Propriété intellectuelle 


\section{Valeurs et valorisations du territoire}

Article collectif

Maria Basile, Anne Douvin, Harold Hurel, Karim Mosbah, France Poulain, Chakib Benramdane, Yann Renaud and Clément Orillard 